\title{
Association between ERCC1 and ERCC2 gene polymorphisms and susceptibility to pancreatic cancer
}

\author{
M.G. He, K. Zheng, D. Tan and Z.X. Wang \\ Department of Hepatobiliary Surgery, \\ Nuclear Industry 215 Hospital of Shaanxi Province, Xianyang, China \\ Corresponding author: K. Zheng \\ E-mail: kangzhengz@163.com \\ Genet. Mol. Res. 15 (1): gmr.15017879 \\ Received October 21, 2015 \\ Accepted January 13, 2016 \\ Published March 31, 2016 \\ DOI http://dx.doi.org/10.4238/gmr.15017879
}

ABSTRACT. We conducted a study to investigate the association between ERCC1 (rs3212986) and ERCC2 (rs13181) gene polymorphisms and the risk of pancreatic cancer in a Chinese population. A total of 217 pancreatic cancer patients and 244 control subjects were recruited from the Nuclear Industry 215 Hospital of Shaanxi Province between February 2013 and December 2014. Genomic DNA was extracted from peripheral blood samples using a TIANamp Blood DNA Kit (Tiangen, Beijing, China) according to the manufacturer's instructions. The ERCC1 rs3212986 and ERCC2 rs13181 polymorphisms were genotyped by polymerase chain reaction-restriction fragment length of polymorphism. Unconditional logistic regression analyses showed that subjects with the CC genotype of ERCC1 rs3212986 were susceptible to the development of pancreatic cancer when compared with subjects with the AA genotype (OR $=2.57$, $95 \% \mathrm{Cl}=1.34-5.02)$. The ERCC1 rs3212986 gene polymorphism was associated with increased risk of pancreatic cancer in the dominant (OR $=1.54,95 \% \mathrm{Cl}=1.05-2.28)$ and recessive $(\mathrm{OR}=2.22,95 \% \mathrm{Cl}=1.20$ 4.19) models. However, no significant difference was found between the ERCC2 rs13181 polymorphism and the risk of pancreatic cancer in the 
codominant, dominant, and recessive models. We suggest that the ERCC1 rs3212986 polymorphism increases susceptibility to pancreatic cancer in the codominant, dominant, and recessive models, although further studies are needed to confirm our findings.

Key words: ERCC1; ERCC2; Polymorphism; Pancreatic cancer

\section{INTRODUCTION}

Pancreatic cancer is the fourth most common cause of cancer death in the world (Jemal et al., 2011; IARC, 2012). The actual mechanisms underlying the occurrence of pancreatic cancer are largely unknown. The pathogenesis of pancreatic cancer involves many environmental and genetic factors, and it is reported that environmental chemicals exposure, heavy metals, and obesity contribute to the susceptibility of pancreatic cancer (Antwi et al., 2015; Kim and Ahuja, 2015; Zheng et al., 2015). Many studies have shown that genetic factors, such as E-cadherin gene, $\mathrm{X}$-ray repair cross-complementing protein 4 gene, cyclooxygenase-2 gene, and DNA repair genes (Ding and Li, 2015; Shen et al., 2015; Wang et al., 2015; Zhao et al., 2015).

DNA repair gene polymorphisms that can alter the function and efficiency of DNA repair process may contribute to risk of cancer development. Nucleotide excision repair (NER) is a key DNA repair mechanisms that can influence gene-gene rearrangement, translocation, amplification, and deletion (Berwick and Vineis, 2000; Shields and Harris, 2000). Excision repair cross complementation group 1 (ERCC1) and ERCC2 are DNA repair genes with the chromosomal locus 19q13.3; the proteins they encode play an important role in NER (Smith et al., 2000). Currently, few studies have reported the relationship of ERCC1 (rs3212986) and ERCC2 (rs13181) with the development of pancreatic cancer (Jiao et al., 2007; Duell et al., 2008; McWilliams et al., 2008). Therefore, we conducted an investigation of the association between ERCC1 (rs3212986) and ERCC2 (rs13181) gene polymorphisms and the risk of pancreatic cancer in a Chinese population.

\section{MATERIAL AND METHODS}

\section{Patients}

A total of 217 pancreatic cancer patients were recruited from the Nuclear Industry 215 Hospital of Shaanxi Province between February 2013 and December 2014. All the patients with pancreatic cancer were independently diagnosed by two pathologists. During the same time period, a total of 244 controls were selected from the clinics at the Nuclear Industry 215 Hospital of Shaanxi Province, and all the controls were free from cancer and infection diseases, or end-stage liver and kidney diseases. All participants signed informed consent before the study commenced. The protocol of our study was approved by the Ethics Committee of the Nuclear Industry 215 Hospital of Shaanxi Province.

After enrollment into the study, the demographic, lifestyle and clinical data for all the participants, including age, gender, tobacco smoking habits, alcohol consumption, body mass index (BMI), diabetes, and family history of cancer, were collected from the medical records. 


\section{DNA extraction and genotyping}

Peripheral blood $(5 \mathrm{~mL})$ was obtained from each patient with pancreatic cancer and from the control subjects, and was stored in ethylenediaminetetraacetic acid tubes at $-20^{\circ} \mathrm{C}$ until required. Genomic DNA was extracted from the peripheral blood samples using a TIANamp Blood DNA Kit (Tiangen, Beijing, China) according to the manufacturer instructions. The ERCC1 rs3212986 and ERCC2 rs13181 polymorphisms were genotyped by polymerase chain reactionrestriction fragment length of polymorphism (PCR-RFLP). The forward and reverse primers for ERCC1 rs3212986 were designed using the Sequenom Assay Design 3.1 software (Table 1). The forward and reverse primers for ERCC1 rs3212986 were for quality control; $10 \%$ of the samples were selected for duplicate testing, and the consistency was $100 \%$. The PCR products were visualized by agarose gel electrophoresis and UV light.

\begin{tabular}{l} 
Table 1. Polymerase chain reaction (PCR) primers for ERCC1 rs3212986 and ERCC2 rs13181, and fragment sizes. \\
\begin{tabular}{l|l|c}
\hline SNP & Primer sequences & Fragment size \\
\hline ERCC1 rs3212986 & 5'-TGAGCCAATTCAGCCACT-3' & 380 bp \\
\hline ERCC2 rs1318 & 5'-TAGTTCCTCAGTTTCCCG-3' & 161 bp \\
\hline
\end{tabular} \\
\hline
\end{tabular}

\section{Statistical analysis}

Continuous and categorical variables are reported as means \pm standard deviation and $\mathrm{N}(\%)$ of study participants. The demographic and lifestyle data for the patients with pancreatic cancer and the control subjects were compared using the chi-square test. A goodness-offit chi-square test was used to assess agreement with the Hardy-Weinberg equilibrium in genotype frequencies in the control subjects. Unconditional logistic regression was performed to assess the role of ERCC1 rs3212986 and ERCC2 rs13181 polymorphisms and the risk of acute pancreatitis, and odds ratios (ORs) and the corresponding 95\% confidence intervals $(95 \% \mathrm{Cls})$ were taken to estimate the results. The main homozygotes of ERCC1 rs 3212986 and ERCC2 rs13181 were considered as the reference group. All $\mathrm{P}$ values were 2-sided, and $P$ values less than 0.05 were regarded as statistically significant. All statistical analyses were conducted using version 16.0 of the SPSS ${ }^{\circledR}$ statistical package for Windows ${ }^{\circledR}$ (SPSS Inc., Chicago, IL, USA).

\section{RESULTS}

This study comprised $159(73.27 \%)$ males and 58 (26.73\%) females with pancreatic cancer, and $160(65.57 \%)$ male and $84(34.43 \%)$ female control subjects (Table 2). The mean ages of pancreatic cancer patients and control subjects were $64.64 \pm 11.53$ and $65.65 \pm 10.74$ years, respectively. Using the chi-square test, there were significant differences in tobacco smoking $\left(\chi^{2}\right.$ $=6.46, \mathrm{P}=0.01)$, alcohol consumption $\left(\chi^{2}=5.10, \mathrm{P}=0.02\right)$, and BMI between the patients with pancreatic cancer and the controls. However, no significant differences were found in age $\left(\chi^{2}=\right.$ $0.40, P=0.53)$, gender $\left(\chi^{2}=3.19, P=0.07\right)$, diabetes $\left(\chi^{2}=1.41, P=0.24\right)$, and family history of cancer $\left(\chi^{2}=2.95, \mathrm{P}=0.09\right)$. 
Table 2. Demographic and lifestyle data for patients with pancreatic cancer and control subjects.

\begin{tabular}{|c|c|c|c|c|c|c|}
\hline Variables & Patients $(\mathrm{N}=217)$ & $\%$ & Controls $(\mathrm{N}=244)$ & $\%$ & $\chi^{2}$-test & $P$ value \\
\hline \multicolumn{7}{|l|}{ Age (years) } \\
\hline$\leq 60$ & 95 & 43.78 & 114 & 46.72 & & \\
\hline$>60$ & 122 & 56.22 & 130 & 53.28 & 0.40 & 0.53 \\
\hline \multicolumn{7}{|l|}{ Gender } \\
\hline Male & 159 & 73.27 & 160 & 65.57 & & \\
\hline Female & 58 & 26.73 & 84 & 34.43 & 3.19 & 0.07 \\
\hline \multicolumn{7}{|c|}{ Smoking tobacco } \\
\hline Never & 97 & 44.70 & 138 & 56.56 & & \\
\hline Sometimes & 120 & 55.30 & 106 & 43.44 & 6.46 & 0.01 \\
\hline \multicolumn{7}{|c|}{ Alcohol consumption } \\
\hline Never & 138 & 63.59 & 179 & 73.36 & & \\
\hline Sometimes & 79 & 36.41 & 65 & 26.64 & 5.10 & 0.02 \\
\hline \multicolumn{7}{|c|}{ Body mass index (BMI) } \\
\hline$\leq 25$ & 135 & 62.21 & 187 & 76.64 & & \\
\hline$>25$ & 82 & 37.79 & 57 & 23.36 & 11.35 & 0.001 \\
\hline \multicolumn{7}{|l|}{ Diabetes } \\
\hline No & 40 & 18.43 & 35 & 14.34 & & \\
\hline Yes & 177 & 81.57 & 209 & 85.66 & 1.41 & 0.24 \\
\hline \multicolumn{7}{|c|}{ Family history of cancer } \\
\hline No & 37 & 17.05 & 28 & 11.48 & & \\
\hline Yes & 180 & 82.95 & 216 & 88.52 & 2.95 & 0.09 \\
\hline
\end{tabular}

The genotype distributions of ERCC1 rs3212986 were significantly different between the patients with pancreatic cancer and the control subjects $\left(\chi^{2}=9.67, P=0.01\right)$, but no significant difference was found in ERCC2 rs13181 ( $\left.\chi^{2}=1.73, P=0.01\right)$ (Table 3). Using the chi-square test, we found that the genotype distributions of ERCC1 rs3212986 and ERCC2 rs13181 agreed with the Hardy-Weinberg equilibrium in the patients with pancreatic cancer and the controls.

Table 3. Genotype distributions of ERCC1 rs3212986 and ERCC2 rs13181 polymorphisms between patients with
pancreatic cancer and controls.
\begin{tabular}{l|c|c|c|c|c|c|c|c}
\hline SNP & Patients & $\%$ & Controls & $\%$ & $\chi^{2}$ test & P value & \multicolumn{2}{|c}{ P for HWE } \\
\cline { 3 - 8 } & & & & & & & & \\
\hline ERCC1 rs3212986 & & & & & & & \\
\hline AA & 84 & 38.71 & 120 & 49.18 & & & & \\
\hline AC & 97 & 44.70 & 103 & 42.21 & & & & \\
\hline CC & 36 & 16.59 & 21 & 8.61 & 9.67 & 0.01 & 0.38 & 0.75 \\
\hline ERCC2 rs13181 & 119 & 54.84 & 143 & 58.61 & & & & \\
\hline CC & 78 & 35.94 & 86 & 35.25 & & & & \\
\hline AC & 20 & 9.22 & 15 & 6.15 & 1.73 & 0.42 & 0.17 & 0.67 \\
\hline AA & &
\end{tabular}

SNP = single nucleotide polymorphism; HWE = Hardy-Weinberg equilibrium.

Unconditional logistic regression analyses showed that subjects with the CC genotype of ERCC1 rs3212986 were susceptible to pancreatic cancer compared with those with the AA genotype $(\mathrm{OR}=2.57,95 \% \mathrm{Cl}=1.34-5.02)$ (Table 4). Moreover, the ERCC1 rs3212986 gene polymorphism was associated with increased risk of pancreatic cancer in the dominant (OR $=1.54$, $95 \% \mathrm{Cl}=1.05-2.28)$ and recessive $(\mathrm{OR}=2.22,95 \% \mathrm{Cl}=1.20-4.19)$ models. However, no significant difference was found between the ERCC2 rs13181 polymorphism and the risk of pancreatic cancer in the codominant, dominant, and recessive models. 


\begin{tabular}{|c|c|c|c|c|c|c|}
\hline SNP & Patients & $\%$ & Controls & $\%$ & OR $(95 \% \mathrm{Cl})^{1}$ & $P$ value \\
\hline \multicolumn{7}{|c|}{ ERCC1 rs3212986 } \\
\hline \multicolumn{7}{|c|}{ Codominant } \\
\hline AA & 84 & 38.71 & 120 & 49.18 & 1.0 (Ref.) & - \\
\hline $\mathrm{AC}$ & 97 & 44.70 & 103 & 42.21 & $1.35(0.89-2.03)$ & 0.14 \\
\hline $\mathrm{CC}$ & 36 & 16.59 & 21 & 8.61 & $2.57(1.34-5.02)$ & 0.002 \\
\hline \multicolumn{7}{|c|}{ Dominant } \\
\hline AA & 84 & 38.71 & 120 & 49.18 & 1.0 (Ref.) & - \\
\hline$A C+C C$ & 133 & 61.29 & 124 & 50.82 & $1.54(1.05-2.28)$ & 0.02 \\
\hline \multicolumn{7}{|c|}{ Recessive } \\
\hline$A A+A C$ & 181 & 83.41 & 223 & 91.39 & 1.0 (Ref.) & - \\
\hline $\mathrm{CC}$ & 36 & 16.59 & 21 & 8.61 & $2.22(1.20-4.19)$ & 0.006 \\
\hline \multicolumn{7}{|c|}{ ERCC2 rs13181 } \\
\hline \multicolumn{7}{|c|}{ Codominant } \\
\hline $\mathrm{CC}$ & 119 & 54.84 & 143 & 58.61 & 1.0 (Ref.) & - \\
\hline $\mathrm{AC}$ & 78 & 35.94 & 86 & 35.25 & $1.09(0.72-1.64)$ & 0.67 \\
\hline AA & 20 & 9.22 & 15 & 6.15 & $1.60(0.74-3.52)$ & 0.19 \\
\hline \multicolumn{7}{|c|}{ Dominant } \\
\hline $\mathrm{CC}$ & 119 & 54.84 & 143 & 58.61 & 1.0 (Ref.) & - \\
\hline$A C+A A$ & 98 & 45.16 & 101 & 41.39 & $1.17(0.79-1.72)$ & 0.41 \\
\hline \multicolumn{7}{|c|}{ Recessive } \\
\hline $\mathrm{CC}+\mathrm{AC}$ & 197 & 90.78 & 229 & 93.85 & 1.0 (Ref.) & - \\
\hline $\mathrm{AA}$ & 20 & 9.22 & 15 & 6.15 & $1.55(0.73-3.34)$ & 0.21 \\
\hline
\end{tabular}

SNP = single nucleotide polymorphism. ${ }^{1}$ Adjusted for gender, age, smoking tobacco, alcohol consumption, and BMI.

\section{DISCUSSION}

Recently, several studies have reported that SNPs in DNA repair genes, such as XRCC1, XRCC4, and MGMT, are associated with susceptibility to pancreatic cancer (Jiang et al., 2013; Schmitt et al., 2014; Shen et al., 2015). We performed an investigation to assess the correlation between ERCC1 and ERCC2 gene polymorphisms and susceptibility to pancreatic cancer, and found that the ERCC1 rs3212986 polymorphism was associated with increased risk of pancreatic cancer in the codominant, dominant, and recessive models.

Previous epidemiologic studies have reported the ERCC1 rs3212986 polymorphism could influence the development of several kinds of cancers, such as lung cancer, colorectal cancer, breast cancer, and glioblastoma (Dong et al., 2014; Hou et al., 2014; Pei et al., 2014; Lee et al., 2015). Dong et al. (2014) have reported that the ERCC1 rs3212986 genetic polymorphism may be involved in the development of glioblastoma in the Han Chinese population. Hou et al. (2014) carried out a casecontrol study in a Chinese population, and found a statistically significant association between ERCC1 rs3212986 genetic variation and risk of colorectal cancer. Pei et al. (2014) conducted a study comprised of 417 breast cancer patients and 417 cancer-free controls, and demonstrated a significant relationship between ERCC1 rs3212986 genetic polymorphism and breast cancer in a Chinese population. Therefore, genetic variations in ERCC1 could influence the susceptibility to cancers.

To date, the authors of only three studies have reported an association between ERCC1 and ERCC2 gene polymorphisms and the development of pancreatic cancer (Jiao et al., 2007; Duell et al., 2008; McWilliams et al., 2008). McWilliams et al. (2008) conducted a case-control study with 481 patients and 625 controls, and found that an ERCC2 gene polymorphism was associated with an increased risk for pancreatic cancer. Jiao et al. (2007) reported that the ERCC2 rs13181 polymorphism could be associated with an increased risk for pancreatic cancer. Duell et al. (2008) also found that the ERCC2 rs13181 polymorphism could influence the development of pancreatic cancer. In our study, we found that the ERCC1 rs3212986 gene polymorphism was associated with 
the development of pancreatic cancer, but there was no association between ERCC2 rs13181 and the risk of this cancer. The results of our study are different from those previously reported. The discrepancies may be caused by differences in ethnicity, selection of controls, and sample sizes.

There are two limitations in the present study. First, the study subjects were recruited from one single hospital in China, which may induce selection bias in this study. However, the genotype distributions of ERCC1 rs3212986 and ERCC2 rs13181 agreed with the Hardy-Weinberg equilibrium in both patients and controls, which suggests the study subjects have representative of the general population. Second, the sample size of this study is relatively small, which may reduce the statistical power to find differences in groups. Therefore, further studies with more sample size are expected to confirm our findings.

We suggest that the ERCC1 rs3212986 polymorphism increases susceptibility to pancreatic cancer in the codominant, dominant, and recessive models, although further studies are needed to confirm our findings.

\section{Conflicts of interest}

The authors declare no conflict of interest.

\section{ACKNOWLEDGMENTS}

We thank the great help from staffs in our hospital for collecting blood samples.

\section{REFERENCES}

Antwi SO, Eckert EC, Sabaque CV, Leof ER, et al. (2015). Exposure to environmental chemicals and heavy metals, and risk of pancreatic cancer. Cancer Causes Control 26: 1583-1591. http://dx.doi.org/10.1007/s10552-015-0652-y

Berwick M and Vineis P (2000). Markers of DNA repair and susceptibility to cancer in humans: an epidemiologic review. J. Natl. Cancer Inst. 92: 874-897.

Ding Y and Li LN (2015). Association between single nucleotide polymorphisms of X-ray repair cross-complementing protein 4 gene and development of pancreatic cancer. Genet. Mol. Res. 14: 9626-9632. http://dx.doi.org/10.4238/2015. August.14.25

Dong YS, Hou WG, Li XL, Jin TB, et al. (2014). Genetic association of CHEK2, GSTP1, and ERCC1 with glioblastoma in the Han Chinese population. Tumour Biol. 35: 4937-4941. http://dx.doi.org/10.1007/s13277-014-1648-z

Duell EJ, Bracci PM, Moore JH, Burk RD, et al. (2008). Detecting pathway-based gene-gene and gene-environment interactions in pancreatic cancer. Cancer Epidemiol. Biomarkers Prev. 17: 1470-1479. http://dx.doi.org/10.1158/1055-9965.EPI-07-2797

Hou R, Liu Y, Feng Y, Sun L, et al. (2014). Association of single nucleotide polymorphisms of ERCC1 and XPF with colorectal cancer risk and interaction with tobacco use. Gene 548: 1-5. http://dx.doi.org/10.1016/j.gene.2014.05.025

International Agency for Research on Cancer (IARC) (2012). GLOBOCAN 2012: Estimated Cancer Incidence, Mortality and Prevalence Worldwide in 2012. http://globocan.iarc.fr/Pages/fact sheets population.aspx. Accessed December 30, 2015.

Jemal A, Bray F, Center MM, Ferlay J, et al. (2011). Global cancer statistics. CA Cancer J. Clin. 61: 69-90. http://dx.doi. org/10.3322/caac.20107

Jiang H, Wu D, Ma D, Lin G, et al. (2013). Association between X-ray repair cross-complementation group 1 rs25487 polymorphism and pancreatic cancer risk. Tumour Biol. 34: 3417-3421. http://dx.doi.org/10.1007/s13277-013-0914-9

Jiao L, Hassan MM, Bondy ML, Abbruzzese JL, et al. (2007). The XPD Asp312Asn and Lys751GIn polymorphisms, corresponding haplotype, and pancreatic cancer risk. Cancer Lett. 245: 61-68. http://dx.doi.org/10.1016/j.canlet.2005.12.026

Kim VM and Ahuja N (2015). Early detection of pancreatic cancer. Chin. J. Cancer Res. 27: 321-331.

Lee MS, Liu CY, Su L and Christiani DC (2015). Polymorphisms in ERCC1 and ERCC2/XPD genes and carcinogen DNA adducts in human lung. Lung Cancer 89: 8-12.

McWilliams RR, Bamlet WR, Cunningham JM, Goode EL, et al. (2008). Polymorphisms in DNA repair genes, smoking, and 
pancreatic adenocarcinoma risk. Cancer Res. 68: 4928-4935. http://dx.doi.org/10.1158/0008-5472.CAN-07-5539

Pei XH, Yang Z, Lv XQ and Li HX (2014). Genetic variation in ERCC1 and XPF genes and breast cancer risk. Genet. Mol. Res. 13: 2259-2267. http://dx.doi.org/10.4238/2014.March.31.6

Schmitt AM, Pavel M, Rudolph T, Dawson H, et al. (2014). Prognostic and predictive roles of MGMT protein expression and promoter methylation in sporadic pancreatic neuroendocrine neoplasms. Neuroendocrinology 100: 35-44. http://dx.doi. org/10.1159/000365514

Shen Q, Tian Y, Li K, Jiang Q, et al. (2015). Association of single nucleotide polymorphisms of DNA repair gene and susceptibility to pancreatic cancer. Int. J. Clin. Exp. Pathol. 8: 3180-3185.

Shields PG and Harris CC (2000). Cancer risk and low-penetrance susceptibility genes in gene-environment interactions. J. Clin. Oncol. 18: 2309-2315.

Smith JS, Tachibana I, Pohl U, Lee HK, et al. (2000). A transcript map of the chromosome 19q-arm glioma tumor suppressor region. Genomics 64: 44-50. http://dx.doi.org/10.1006/geno.1999.6101

Wang Y, Jiang H, Liu T, Tang W, et al. (2015). Cyclooxygenase-2 -1195G>A (rs689466) polymorphism and cancer susceptibility: an updated meta-analysis involving 50,672 subjects. Int. J. Clin. Exp. Med. 8: 12448-12462.

Zhao L, Wang YX, Xi M, Liu SL, et al. (2015). Association between E-cadherin (CDH1) polymorphisms and pancreatic cancer risk in Han Chinese population. Int. J. Clin. Exp. Pathol. 8: 5753-5760.

Zheng Z, Zheng R, He Y, Sun X, et al. (2015). Risk factors for pancreatic cancer in China: a multicenter case-control study. J. Epidemiol. 26: 64-70. 